\title{
Ultrasonographic Findings of Medullary Thyroid Carcinoma: a Comparison with Papillary Thyroid Carcinoma
}

Sung-Hun Kim, MD ${ }^{1}$

Bum-Soo Kim, MD ${ }^{1}$

So-Lyung Jung, MD'

Jung-Whee Lee, MD'

Po-Sung Yang, MD ${ }^{1}$

Bong-Joo Kang, MD ${ }^{1}$

Hyun-Wook Lim, MD'

Jee-Young Kim, MD ${ }^{1}$

In-Yong Whang, $\mathrm{MD}^{1}$

Heuk-Sang Kwon, MD²

Chan-Kwon Jung, MD $^{3}$

Index terms:

Thyroid

Thyroid, neoplasms

Thyroid, US

DOI:10.3348/kjr.2009.10.2.101

Korean J Radiol 2009; 10:101-105

Received January 15, 2008; accepted after revision September 30, 2008.

Departments of ${ }^{1}$ Radiology, ${ }^{2}$ Internal Medicine and ${ }^{3}$ Pathology, College of Medicine, The Catholic University of Korea

Address reprint requests to: Bum Soo Kim, MD, Department of Radiology, Kangnam St. Mary's Hospital, The Catholic University of Korea, 505 Banpo-dong, Seocho-gu, Seoul 137-040, Korea.

Tel. (822) 590-1580

Fax. (822) 599-6771

e-mail: bumrad@catholic.ac.kr
Objective: This study was designed to evaluate the ultrasonographic (US) findings of medullary thyroid carcinoma (MTC) as compared to findings for papillary thyroid carcinoma (PTC).

Materials and Methods: The study included 21 cases of MTC that were surgically diagnosed between 2002 and 2007 and 114 cases of PTC that were diagnosed in 2007. Two radiologists reached a consensus in the evaluation of the US findings. The US findings were classified as recommended by the Thyroid Study Group of the Korean Society of Neuroradiology and Head and Neck Radiology (KSNHNR) and each nodule was identified as suspicious malignant, indeterminate or probably benign. The findings of medullary and papillary carcinomas were compared with use of the chi-squared test.

Results: The common US findings for MTCs were solid internal content (91\%), an ovoid to round shape (57\%), marked hypoechogenicity (52\%) and calcifications (52\%). Among the 21 cases of MTC nodules, 17 (81\%) were classified as suspicious malignant nodules. The mean size (longest diameter) of MTC nodules was $19 \pm 13.9 \mathrm{~mm}$ and the mean size (longest diameter) of PTC nodules was 11 $\pm 7.4 \mathrm{~mm}$; this difference was statistically significant $(p<0.05)$. An ovoid to round shape was more prevalent for MTC lesions than for PTC lesions $(p<0.05)$.

Conclusion: The US criteria for suspicious malignant nodules as recommended by the Thyroid Study Group of the KSNHNR correspond to most MTC cases. The US findings for MTC are not greatly different from PTC except for the prevalence of an ovoid to round shape.

$\mathrm{M}$ edullary thyroid carcinoma (MTC) accounts for 3.5-10\% of all thyroid malignancies ( 1 ) and lesions are derived from the parafollicular $\mathrm{C}$-cells that produce calcitonin (2). The serum calcitonin level is known as a sensitive and specific marker for MTC. However, not all MTCs secrete calcitonin (3), and hypercalcitoninemia is known to be associated with chronic thyroiditis and $\mathrm{C}$-cell hyperplasia in addition to MTC (4). Routine measurement of plasma calcitonin levels in patients who have thyroid nodules has not been widely adopted (5). Therefore, knowledge of the imaging characteristics of MTC is as important as the serum calcitonin level for the early detection and precise diagnosis of MTC. Numerous studies that have evaluated the ultrasonographic (US) findings of malignant thyroid nodules have been conducted (6-11). M ost studies have focused on papillary thyroid carcinomas (PTCs), which account for more than $70 \%$ of all malignant nodules (1013). Studies that have evaluated the US findings of MTC are rare $(14,15)$. In this study, we have evaluated the US findings of MTC as compared with the US findings of PTC. 


\section{MATERIALS AND METHODS}

\section{Patients}

This study included 21 cases (18 patients; 15 females and 3 males; age range, 26-70 years; mean patient age, 55 years) that were surgically diagnosed as an MTC between 2002 and 2007. Three patients had bilateral MTCs (16.7\%). Sixteen patients had a sporadic MTC, and two patients had type Ila multiple endocrine neoplasia (MEN). One MEN type Ila patient had bilateral adrenal pheochromocytomas and another patient had bilateral adrenal hyperplasia. The basal calcitonin level of the 15 MTC patients was measured prior to surgery and in 14 patients the serum calcitonin level was elevated (range, 24.7-355 pg/mL; median level, $171.4 \mathrm{pg} / \mathrm{mL}$ ); the normal range for an immunoradiometric assay is $10 \mathrm{pg} / \mathrm{mL}$. A s the MTC US findings of MTC were to be compared with the PTC US findings, a, control group of 114 PTC cases that were surgically diagnosed during 2007 (99 patients; 85 females and 14 males; age range, 27-76 years; mean age, 50.4 years) was established. Fifteen patients had bilateral PTCs (13.2\%).

\section{US I maging}

High resolution US examinations of the thyroid were performed with a HDI 3000 scanner (A dvanced Technology Laboratories, Philips M edical Systems, Bothell, W A) and a HDI 5000 scanner (Philips Medical Systems) equipped with a 5-10 M Hz linear array transducer.

Examinations were performed by radiology residents and by the radiologists in charge of thyroid imaging (with one to 16 years of experience).

\section{Imaging Analysis and Statistical Analysis}

The US images were analyzed retrospectively in a blind review by two radiologists in charge of thyroid imaging with two and 16 years of experience, respectively. By summarization of the classifications of US findings (size, internal content, shape, margin, echogenicity and calcifications) as recommended by the Thyroid Study Group of the Korean Society of Neuroradiology and Head and Neck Radiology (KSNHNR), each nodule was identified as

Table 1. Comparison of Ultrasonographic Findings of Medullary Thyroid Carcinoma and Papillary Thyroid Carcinoma

\begin{tabular}{|c|c|c|c|}
\hline Ultrasonographic Findings & $\begin{array}{l}\text { Medullary Carcinoma } \\
\qquad(\mathrm{n}=21)\end{array}$ & $\begin{array}{l}\text { Papillary Carcinoma } \\
\qquad(\mathrm{n}=114)\end{array}$ & $P$ value \\
\hline Lesion size & $19 \pm 13.9 \mathrm{~mm}$ & $11 \pm 7.5 \mathrm{~mm}$ & $<0.05$ \\
\hline \multicolumn{4}{|l|}{ Internal content } \\
\hline solid & $19(90.5 \%)$ & $110(96.5 \%)$ & 0.219 \\
\hline predominantly solid & $2(9.5 \%)$ & $4(3.5 \%)$ & \\
\hline predominantly cystic & $0(0 \%)$ & $0(0 \%)$ & \\
\hline cystic & $0(0 \%)$ & $0(0 \%)$ & \\
\hline \multicolumn{4}{|l|}{ Shape } \\
\hline ovoid to round & $12(57.1 \%)$ & $29(25.4 \%)$ & $<0.05$ \\
\hline *taller than wide & $4(19.0 \%)$ & $48(42.1 \%)$ & \\
\hline irregular & $5(23.8 \%)$ & 37 (32.5\%) & \\
\hline \multicolumn{4}{|l|}{ Margin } \\
\hline smooth & $4(19.0 \%)$ & $22(19.3 \%)$ & 0.964 \\
\hline *spiculated & 9 (42.8\%) & $44(38.6 \%)$ & \\
\hline ill-defined & $8(38.1 \%)$ & $48(42.1 \%)$ & \\
\hline \multicolumn{4}{|l|}{ Echogenicity } \\
\hline${ }^{*}$ markedly hypoechoic & $11(52.4 \%)$ & $65(57.0 \%)$ & 0.894 \\
\hline hypoechoic & $9(42.9 \%)$ & $42(36.8 \%)$ & \\
\hline isoechoic & $1(4.8 \%)$ & $5(4.4 \%)$ & \\
\hline hyperechoic & $0(0 \%)$ & $2(1.8 \%)$ & \\
\hline \multicolumn{4}{|l|}{ Calcifications } \\
\hline no calcifications & $10(47.6 \%)$ & $37(32.5 \%)$ & 0.348 \\
\hline${ }^{*}$ microcalcifications & $6(28.6 \%)$ & $53(46.5 \%)$ & \\
\hline${ }^{*}$ macrocalcifications & $5(23.8 \%)$ & $21(18.4 \%)$ & \\
\hline rim calcifications & $0(0 \%)$ & $3(2.6 \%)$ & \\
\hline
\end{tabular}

Note - * If nodule had any one of these features on ultrasonography, it was classified as suspicious malignant nodule. 


\section{US Findings of Medullary Thyroid Carcinoma}

suspicious malignant, indeterminate or probably benign (6). An analysis for distant or regional metastases, including lymph node metastases, was not performed in this study. W ith respect to the size of the nodules, the longest diameter measured by US was selected and was expressed as the mean \pm standard deviation.

The internal contents of the nodules were defined as solid (a solid component more than $90 \%$ ), predominantly solid (a solid component more than $50 \%$ but less than $90 \%$ ), predominantly cystic (a solid component more than $10 \%$ but less than $50 \%$ ) and cystic (solid component less than $10 \%$ ). The shape of nodules was defined as ovoid to round, taller than wide (the anteroposterior dimension was longer than the transverse diameter), or irregular (neither round to oval nor taller than wide). The border characteristics were defined as smooth, spiculated or ill defined. Echogenicity was defined as markedly hypoechoic (less than the strap muscle echogenicity), hypoechoic (less than the thyroid echogenicity), isoechoic (equal to the thyroid echogenicity) or hyperechoic (greater than the thyroid echogenicity). Calcifications were defined as microcalcifications (tiny punctate hyperechogenicities either with or without acoustic shadowings of less than $1 \mathrm{~mm}$ in diameter), macrocalcifications (larger than $1 \mathrm{~mm}$ in diameter) or rim calcifications. Malignant sonographic characteristics were defined as a shape that was taller than wide, with a spiculated border, marked hypoechogenicity and micro calcifications or macrocalcifications. If a nodule had any one of these features that are suggestive of a malignancy, the lesion was classified as a suspicious malignant nodule. A probably benign nodule was classified

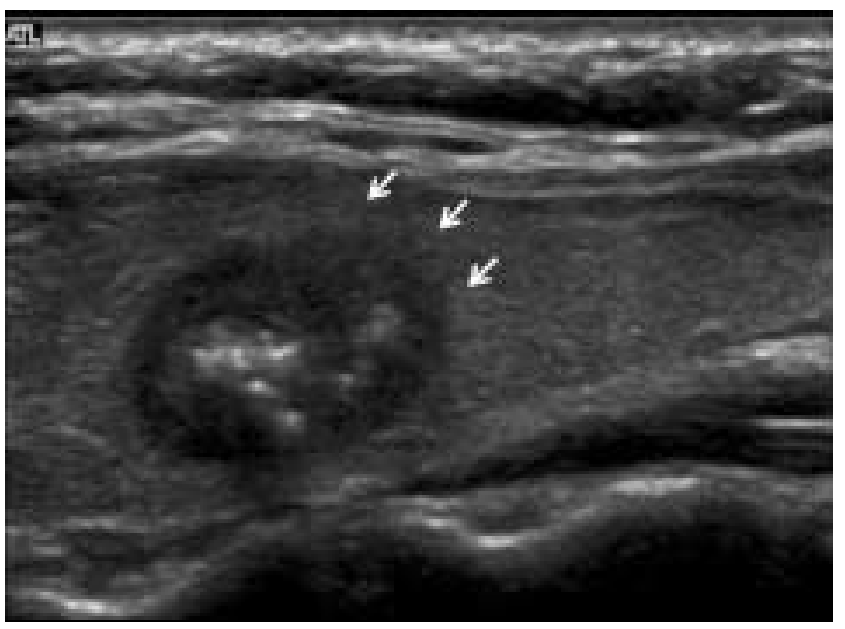

Fig. 1. Ultrasonography performed on 55-year-old female with medullary thyroid carcinoma.

Sagittal scan shows $13 \mathrm{~mm}$, solid, ovoid to round, markedly hypoechoic nodule with spiculated border (arrows) and internal macrocalcifications. This nodule was classified as suspicious malignant. as either completely cystic or predominantly cystic with a comet tail artifact. An indeterminate nodule was defined as a nodule that was not suspicious for malignancy or showed probably benign findings. The findings of medullary and papillary carcinomas were compared with use of the chisquared test. A p-value of less than 0.05 was defined as statistically significant.

\section{RESULTS}

The US findings of the MTCs and PTCs are summarized in the Table 1. For the MTCs, a solid internal content (19 of $21,90.5 \%$ ), ovoid to round shape (12 of $21,57.1 \%$ ), marked hypoechogenicity (11 of $21,52.4 \%$ ), microcalcifications or macrocalcifications (11 of $21,52.4 \%$ ) and a spiculated or ill-defined margin (17 of $21,80.9 \%$ ) were the prevailing findings seen on US. For 21 MTC S, 17 (81\%) were categorized as suspicious malignant nodules, and four (19\%) were categorized as indeterminate nodules (Figs. 1, 2). N one of the lesions were categorized as probably benign nodules. For the PTCS, the prevailing findings as seen on US were a solid internal content (110 of 114, $96.5 \%$ ), taller than wide shape (48 of $114,48 \%$ ), irregular border (48 of 114, $42.1 \%$ ), marked hypoechogenicity (65 of $114,57.0 \%)$ and microcalcifications or macrocalcifications (74 of 114, 64.9\%) ). For 114 PTCs, 107 (94\%) were categorized as suspicious malignant nodules and seven (6\%) were categorized as indeterminate nodules (Fig. 3). The mean size $(19 \pm 13.9 \mathrm{~mm}$ vs. $11 \pm 7.5 \mathrm{~mm})$ and ovoid to round shape ( $57.1 \%$ vs. $25.4 \%$ ) were statistically different between the MTCs and PTCs. However, the

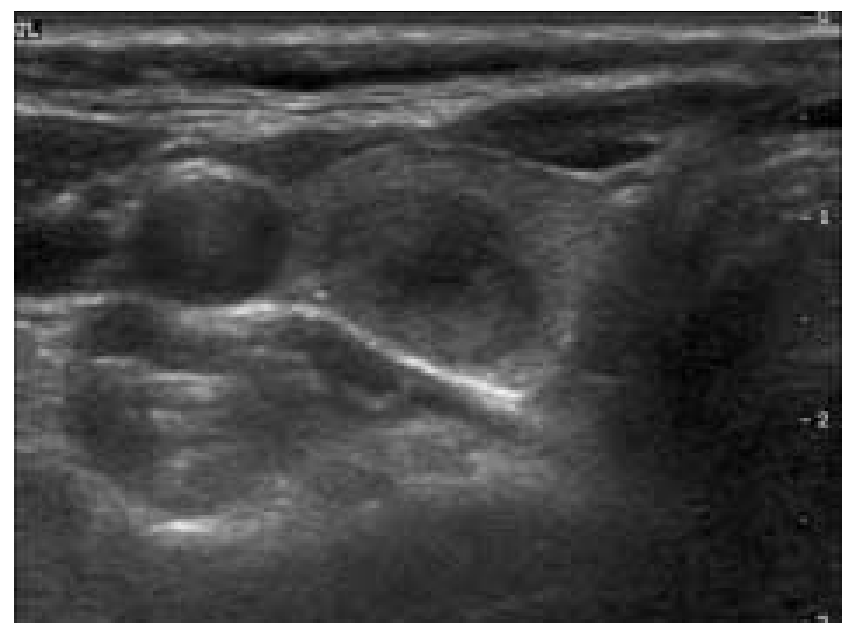

Fig. 2. Ultrasonography performed on 61-year-old female with medullary thyroid carcinoma.

Transverse scan shows $18 \mathrm{~mm}$, solid, ovoid to round, hypoechoic nodule with smooth border. This nodule was classified as indeterminate. 
internal content, margin, echogenicity and calcifications were not statistically significantly different between the two types of nodules. Most of the MTC and PTC nodules were classified as suspicious malignant; however, the frequency of an indeterminate nodule was higher for the MTCs than for the PTCs.

\section{DISCUSSION}

Eighty to ninety percent of MTCs have been considered as sporadic and the rest have been classified as hereditary (1). The familial form of the tumor usually occurs as a component of type lla MEN (Sipple syndrome), which is characterized by the combination of an MTC, adrenal pheochromocytoma and hyperplasia of the parathyroid glands. MEN type IIb is a highly unusual form of the MEN II syndrome and consists of elements of type Ila and additional features of marfanoid habitus, mucosal neuromas and intestinal ganglioneuromatosis. In the present study, 16 patients were categorized as having the sporadic form and two patients were categorized as having MEN type lla.

Fine needle aspiration (FNA) of thyroid nodules has become one of the most useful, safe and accurate methods used to diagnose thyroid pathology. US findings are important to evaluate and prioritize nodules during FNA . US findings have been reported to be of great help to distinguish malignant from benign nodules $(6-11,13)$. The US findings that have been reported for malignant thyroid nodules have included completely solid or predominantly solid nodules, hypoechogenicity as compared with the strap muscles, an irregular margin, intranodular microcalcifications, a taller than wide orientation and increased intranodular vascularity. Moon et al. (6) reported in a multicenter retrospective study the US findings of benign and malignant thyroid nodules (6). The Thyroid Study Group of the KSNHNR organized this study, which was performed on patients from nine university hospitals and large general hospitals in the Republic of Korea. The findings suggested malignancy in nodules with a taller than wide shape, spiculated margin, marked hypoechogenicity, and intranodular calcifications (including microcalcifications or macrocalcifications). The findings of the study demonstrated a high sensitivity $(93.8 \%)$ and a high negative predictive value (95.9\%). In most cases, the malignant nodules that were included in the Moon et al. (6) study and similar studies were PTCs, and most of the PTCs correlated with the US findings of malignant thyroid nodules (10-13). However, studies on the US findings of MTC are not common $(14,15)$. Gorman et al. (14) reported on the high-resolution US findings of MTC in 1987. All of

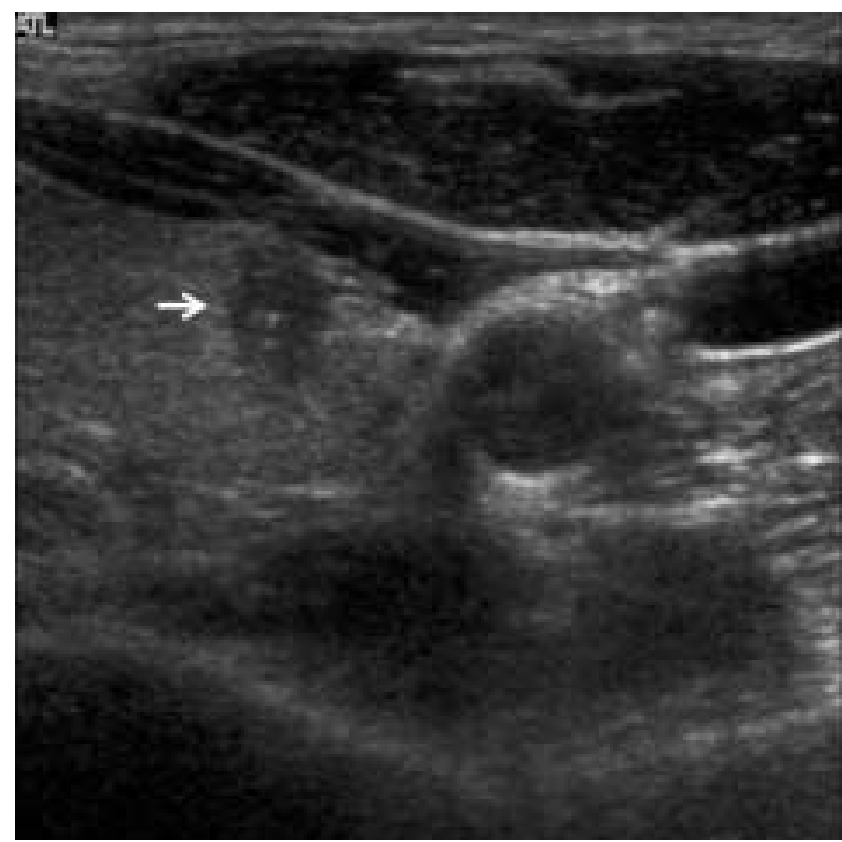

Fig. 3. Ultrasonography performed on 51-year-old male with papillary thyroid carcinoma.

Transverse scan shows $6 \mathrm{~mm}$, solid, taller than wide, hypoechoic nodule (arrow) with spiculated border and internal microcalcifications. This lesion was classified as suspicious malignant nodule.

the tumors (six lesions in six patients) appeared hypoechoic and were relatively well defined. Bright echogenic foci were reported in five patients $(83.3 \%)$, and this finding was supported by the histological finding of focal deposits of calcium surrounded by amyloid. In 2002, Saller et al. (15) reported the US findings of 19 MTC cases. All of the cases showed hypoechogenicity. The present study evaluated 21 MTC cases, a higher number than in previous studies. Most MTC nodules $(95.3 \%)$ were markedly hypoechoic $(52 \%)$ or hypoechoic $(42.9 \%)$, and our findings are similar to the findings of the above two studies $(14,15)$. In the current study, intranodular calcifications were observed in $52 \%$ of the MTC patients. A s compared to the results of the Gorman et al. (83.3\%) and Saller et al. (95\%) studies, we found a low calcification rate.

Studies comparing the US findings of MTC with PTC have not been previously conducted and we compared and analyzed the US findings of 21 MTC cases and 114 PTC cases. The mean size of MTC nodules was larger than that of PTC nodules ( $19 \pm 13.9 \mathrm{~mm}$ vs. $11 \pm 7.5 \mathrm{~mm}, \mathrm{p}<$ 0.05). In a comparison of the US findings, $57 \%$ of MTCS and $25 \%$ of PTCs exhibited an ovoid to round shape, which was significantly higher for the MTC nodules $(p<$ 0.05). However, internal content, margin, echogenicity and frequency of calcifications were not significantly different between MTCs and PTCs. Most MTC (80.9\%) and PTC $(93.9 \%)$ nodules were classified as suspicious malignant 


\section{US Findings of Medullary Thyroid Carcinoma}

nodules. However, in a comparison of MTCs with PTCS, suspicious malignant nodules were found less frequently and indeterminate nodules were found more frequently in MTC than in PTC. This finding can be attributed to a significantly higher frequency of ovoid to round shape in MTC, which is not a suspicious malignant feature. Both MTCs and PTCs have been associated with calcifications more than other thyroid malignancies. The association of an MTC with amyloid deposition pathologically distinguishes this type of tumor from other thyroid malignancies (16). A myloid deposits may be associated with reactive fibrosis and calcified deposits that give rise to characteristically dense, irregular foci throughout the tumor mass. This observation is in contrast with the faint homogeneous calcifications seen in other thyroid tumors (1). Dense and irregular calcifications are known as a characteristic finding of MTC; these macrocalcifications were seen in five MTC nodules $(23.8 \%)$ and in 21 PTC nodules (18.4\%). Saller et al. (15) defined calcifications longer than $2 \mathrm{~mm}$ as macrocalcifications, and reported the presence of macrocalcifications in 53\% of MTC patients in their study; this frequency was higher than in our study. Chan et al. (11) found that among 55 PTC cases, 11\% were associated with macrocalcifications; this frequency was similar to the frequency seen in the present study. The presence of microcalcifications is a known characteristic finding of PTC and microcalcifications have been reported in $29-59 \%$ of all thyroid carcinomas (17). In our study, microcalcifications were found in $29 \%$ of MTCs and $47 \%$ of PTCs. A ccording to the findings in the study by Chan et al. (11), $42 \%$ of PTCs were associated with microcalcifications, a finding that is similar to our results. Saller et al. (15) reported that microcalcifications less than $2 \mathrm{~mm}$ in length were seen in $42 \%$ of MTCs.

Serum calcitonin levels rise in MTC patients as MTC $s$ are derived from parafollicular C-cells that produce calcitonin (2). However, not all MTCs secrete calcitonin and in particular, more advanced tumors may dedifferentiate with a subsequent decrease in calcitonin production (3). In the present study, the basal calcitonin level was elevated in 14 patients and was within the normal range in one patient. The patient with a normal calcitonin level had a huge, $7 \mathrm{~cm}$ thyroid mass with an extensive necrotic lymph node metastasis and perithyroidal soft tissue invasion. The pathological result was a poorly differentiated pattern of MTC.

In conclusion, the common US features of MTC are a solid internal content, an ovoid to round shape, marked hypoechogenicity and calcifications. Most MTC s showed US findings of suspicious malignant nodules, as reported by the Thyroid Study Group of the K SN HNR. The US findings were not greatly different between MTCs and
PTCs, except that the ovoid to round shape was more abundant in MTCS.

\section{References}

1. McC ook TA, Putman CE, Dale JK, W ells SA. Medullary carcinoma of the thyroid: radiographic features of a unique tumor. AJR Am J Roentgenol 1982;139:149-155

2. Melvin KE, Tashjian AH Jr. The syndrome of excessive thyrocalcitonin produced by medullary carcinoma of the thyroid. Proc Natl Acad Sci USA 1968;59:1216-1222

3. Busnardo B, Girelli ME, Simioni N, Nacamulli D, Busetto E. N onparallel patterns of calcitonin and carcinoembryonic antigen levels in the follow-up of medullary thyroid carcinoma. Cancer 1984;53:278-285

4. Papi G, Corsello SM, Cioni K, Pizzini A M, Corrado S, Carapezzi $C$, et al. Value of routine measurement of serum calcitonin concentrations in patients with nodular thyroid disease: a multicenter study. J Endocrinol Invest 2006;29:427-437

5. Y ou YN, Lakhani V, W ells SA J r, M oley JF. Medullary thyroid cancer. Surg O ncol Clin N Am 2006;15:639-660

6. Moon WJ , Jung SL, Lee JH, Na DG, Baek JH, Lee YH, et al. Benign and malignant thyroid nodules: US differentiationmulticenter retrospective study. Radiology 2008;247:762-770

7. Frates MC, Benson CB, Charboneau JW, Cibas ES, Clark OH, Coleman $B G$, et al. Management of thyroid nodules detected at US: Society of Radiologists in Ultrasound consensus conference statement. Radiology 2005;237:794-800

8. Iannuccilli J D, Cronan JJ , M onchik J M. Risk for malignancy of thyroid nodules as assessed by sonographic criteria: the need for biopsy. J Ultrasound Med 2004;23:1455-1464

9. Kim EK, Park CS, Chung WY, Oh KK, Kim DI, Lee JT, et al. $\mathrm{N}$ ew sonographic criteria for recommending fine-needle aspiration biopsy of nonpalpable solid nodules of the thyroid. AJR Am J Roentgenol 2002;178:687-691

10. Shimura H, Haraguchi K, Hiejima Y, Fukunari N, Fujimoto $Y$, Katagiri $M$, et al. Distinct diagnostic criteria for ultrasonographic examination of papillary thyroid carcinoma: a multicenter study. Thyroid 2005;15:251-258

11. Chan BK, Desser TS, MCD ougall IR, W eigel RJ , J effrey RB J r. Common and uncommon sonographic features of papillary thyroid carcinoma. J Ultrasound Med 2003;22:1083-1090

12. Pellitteri PK, McCaffrey TV. Tumor and tumor-like lesion in thyroid endocrine surgery of the head and neck, 1st ed. Pennsylvania: Singular publish group, 2002:21-47

13. J eh SK, J ung SL, Kim BS, Lee YS. Evaluating the degree of conformity of papillary carcinoma and follicular carcinoma to the reported ultrasonographic findings of malignant thyroid tumor. Korean J Radiol 2007;8:192-197

14. Gorman B, Charboneau JW, James EM, Reading CC, W old LE, Grant CS, et al. Medullary thyroid carcinoma: role of highresolution US. Radiology 1987;162:147-150

15. Saller B, M oeller L, Görges R, J anssen OE, Mann K. Role of conventional ultrasound and color Doppler sonography in the diagnosis of medullary thyroid carcinoma. Exp Clin Endocrinol Diabetes 2002; 110:403-407

16. Williams ED. Histogenesis of medullary carcinoma of the thyroid. J Clin Pathol 1966;19:114-118

17. Hoang JK, Lee WK, Lee M, J ohnson D, Farrell S. US features of thyroid malignancy: pearls and pitfalls. Radiographics 2007;27:847-860 